\title{
Roles of iron and/or arsenic reducing bacteria in controlling the mobilization of arsenic in high arsenic groundwater aquifer
}

\author{
H. Liu, P. Li, Y.H. Wang \& Z. Jiang \\ State Key Laboratory of Biogeology and Environmental Geology, China University of Geosciences, \\ Wuhan, P.R. China
}

\begin{abstract}
To investigate microbial mediated As release and mobilization in the high arsenic groundwater, indigenous iron/As reducing bacteria were isolated from high arsenic groundwater in the Hetao Basin of Inner Mongolia in China. These isolates were identified to be Fe(III) and As(V) reducing (IAR) Shewanella putrefaciens IAR-S1, Fe(III) reducing (IR) S. xiamenensis IR-S2 and Klebsiella oxytoca IR-ZA, and As(V) reducing (AR) Citrobacter freundii AR-C1, Paralostridium bifermentans AR-P1, Klebsiella pneumoniae AR-K1 and Aeromonas hydrophila AR-A1. The incubation results showed that strains IAR-S1, IR-S2 and the control S. oneidensis MR-1 reduced ferrihydrite quickly and re-immobilized As. Strains AR-C1, AR-P1, AR-K1 and AR-A1 reduces $\mathrm{As}(\mathrm{V})$ to As(III), and arsenic (As-tot) was released into the aqueous phase with strain IR-ZA and strain AR-C1.
\end{abstract}

\section{INTRODUCTION}

Arsenic (As) as a toxic metalloid element threatens the health of more than 140 million people worldwide. It is well known that microbes play an important role on mediating As-bearing Fe(III) oxyhydroxides reduction and As mobilization. Whether DIR results in As retention or release is still an international debate topic. Therefore, to investigate microbiallymediated DIR affecting on As release and mobilization in high arsenic groundwater environment in Hetao Basin of Inner Mongolia, the primary objectives of this study were to: 1) isolate and characterize the dissimilatory iron and/or arsenic reducing strains from the high arsenic groundwater area of Hetao Basin; 2) investigate the arsenic mobilization from As-bearing ferrihydrite with different strains.

\section{METHODS/EXPERIMENTAL}

\subsection{Site description and sample collection}

Water samples for bacterial isolation were collected from two tube wells in Hangjinghouqi County of Hetao Basin, where endemic arseniasis is most serious. Groundwater from this region contains high As concentrations up to $1.74 \mathrm{mg} \mathrm{L}^{-1}$.

\subsection{Bacterial isolation and identification Bacterial isolation and identification}

Iron-reducing medium (IRM) or chemically defined medium (CDM) were used to screen iron-reducing and arsenic-reducing bacteria. For isolation, the Hungate roll tube technique was used (Hungate, 1969). All transfers and cultures sampling were performed in an anaerobic chamber with tubes and bottles flushed with $\mathrm{O}_{2}$-free $\mathrm{N}_{2}$ gas.

DNA was extracted from over-night cultures using FastDNA ${ }^{\circledR}$ SPIN Kit for Soil according to manufacturer's protocols (Qbiogene, Inc. CA, USA) and 16S rRNA gene was amplified with the primers $27 \mathrm{~F}$ and 1492R. The 16S rRNA gene sequences were aligned with the closely related sequences in the GenBank database using the BLAST program.

\subsection{Arsenate and ferric reduction assays}

Iron and $\mathrm{As}(\mathrm{V})$ reduction activities of isolated strains were assayed with IRM or CDM, respectively, under anaerobic conditions as previously described by Dai et al. (2016).

$0.8 \mathrm{~mL}$ pre-culture of strain and As-bearing ferrihydrite (As/Fe molar ratios was $1 \%$ ) was transferred into $100 \mathrm{~mL}$ bottles with $80 \mathrm{~mL}$ basal medium (BM) under strictly anaerobic conditions and incubated at $30^{\circ} \mathrm{C}$ in dark with $120 \mathrm{rpm}$. The control experiment was conducted using an autoclaved abiotic sample under the same conditions to confirm only the chemical effect. In order to detect As mobilization with microbial DIR under groundwater conditions of our study area, strains were incubated with artificial groundwater medium (AGM) and natural groundwater instead of BM.

\section{RESULTS}

\subsection{Isolation and identification}

Three iron reducing strains were obtained and referred to as IAR-S1, IR-S2 and IR-ZA, respectively. BLAST analysis in GenBank identified that 
strain IAR-S1 belonged to Shewanella putrefaciens (99.57\%), strain IR-S2 belonged to Shewanellaxiamenensis (99.36\%), and strain IR-ZA belonged to Klebsiella oxytoca $(99.54 \%)$.

Four arsenate reducing strain was obtained and was named as AR-C1, AR-P1, AR-K1 and AR-A1. Phylogenetic analysis places these four strains closest to organisms referring to as Citrobacter freundii, Paralostridium bifermentans, Klebsiella pneumoniae and Aeromonas hydrophila with the similarity of $99.93 \%, 100 \%, 99.94 \%$ and $99.97 \%$, respectively.

\subsection{Iron and arsenic reduction assays}

Three Fe(III)-reducing strains IAR-S1, IR-S2 and IRZA performed relatively quick reducing rates in the initial 1.0 day, and then slowed down in the remaining incubation. Strain IAR-S1 has a comparatively strong iron reducing capability and could reduce $20.00 \mathrm{mM}$ $\mathrm{Fe}(\mathrm{III})$ into $\mathrm{Fe}(\mathrm{II})$ in 1.5 days, while both strain IR-S2 and IR-ZA only could reduce $16 \mathrm{mM}$ and $10 \mathrm{mM}$ in 1.5 days.

In CDM medium, strain AR-C1 could reduce $100 \%$ of $1 \mathrm{mM} \mathrm{As}(\mathrm{V})$ in $72 \mathrm{~h}$ and $75 \%$ of $2.5 \mathrm{mM} \mathrm{As}(\mathrm{V})$ in $120 \mathrm{~h}$ and $23.1 \%$ of $5 \mathrm{mM}$ in $48 \mathrm{~h}$. Strain AR-P1 could reduce $100 \%$ of $1 \mathrm{mMAs}(\mathrm{V})$ in $96 \mathrm{~h}, 77.6 \%$ of $2.5 \mathrm{mM}$ As(V) in $96 \mathrm{~h}$, and $36.9 \%$ of $5 \mathrm{mMAs}(\mathrm{V})$ in $72 \mathrm{~h}$. Strain AR-K1 could reduce $100 \%$ of $1 \mathrm{mM} \mathrm{As}(\mathrm{V})$ in $48 \mathrm{~h}$, $55.8 \%$ of $2.5 \mathrm{mM} \mathrm{As}(\mathrm{V})$ in $84 \mathrm{~h}$, and $33.7 \%$ of $5 \mathrm{mM}$ $\mathrm{As}(\mathrm{V})$ in $48 \mathrm{~h}$. Strain AR-A1 could reduce $100 \%$ of $1 \mathrm{mM} \mathrm{As}(\mathrm{V})$ in $48 \mathrm{~h}, 70.8 \%$ of $2.5 \mathrm{mM} \mathrm{As}(\mathrm{V})$ in $60 \mathrm{~h}$, and $38.3 \%$ of $5 \mathrm{mM} \mathrm{As}(\mathrm{V})$ in $48 \mathrm{~h}$. However, strain IR-S2 and IR-ZA did not show any As(V) reducing ability. IAR-S1 produced $1.00 \mathrm{mM}$ As(III) within 1.0 days, which can reduce both $\mathrm{Fe}(\mathrm{III})$ and $\mathrm{As}(\mathrm{V})$ with glucose as a carbon source.

\subsection{Reduction of As $(V)$-bearing ferrihydrite}

S. oneidensis MR-1 was chosen as the positive control to detect the As mobilization from As-bearing ferrihydrite by DIR. Under $\mathrm{H}_{2} \mathrm{PO}_{4}^{-}$conditions, at the beginning of incubation, the concentration of aqueous total arsenic (As-tot) increased quickly by all strains. However, the decrease of As-tot was observed along with the culture of strain IAR-S1, IR-S2 and MR-1 after the peaks appeared. The fluctuation of As concentration might be due to the aqueous As captured by the

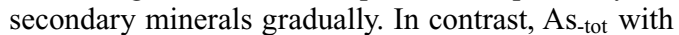
strain IR-ZA and AR-C1 was gradually increased after 12.0 days incubation. The As release with strain IR-ZA could be attributed to the decrease of the surface area of ferrihydrite with the reductive dissolution. On the other hand, more mobile As(III) produced by the As reducing strain AR-C1 increased the aqueous As.

Strains IAR-S1, IR-S2, IR-ZA AR-C1 and MR-1 incubated in the $\mathrm{HCO}_{3}^{-}$conditions, the AGM and the natural groundwater, also performed similar As release and $\mathrm{As}(\mathrm{III})$ reduction patterns with those of $\mathrm{H}_{2} \mathrm{PO}_{4}^{-}$. However, the concentrations of aqueous $\mathrm{As}_{\text {-tot }}$ released by strains were much lower than those of $\mathrm{H}_{2} \mathrm{PO}_{4}^{-}$.

\subsection{Effect of $A s(V)$-reduction or $A s(V)$ concentration on DIR}

To detect the effect of microbial Fe(III) and As(V) reductions on each other, $\mathrm{As}(\mathrm{V})$ reducing strain $\mathrm{AR}-\mathrm{C} 1$ and $\mathrm{Fe}$ (III) reducing strains IR-ZA and IR-S2 (without $\mathrm{As}(\mathrm{V})$ reducing capability) were chosen to co-incubate with As-bearing ferrihydrite. Results showed that both $\mathrm{Fe}(\mathrm{III})$ and $\mathrm{As}(\mathrm{V})$ reductions were improved in the coincubation. $\mathrm{Fe}(\mathrm{II})$ concentrations produced by strains AR-C 1 and IR-ZA after 8.0 days was $0.52 \mathrm{mM}$ higher than sole incubation of strain IR-ZA. More $0.33 \mathrm{mM}$ of $\mathrm{Fe}$ (II) were detected after 8.0 days co-culture of strains AR-C1 and IR-S2, which is higher than sole incubation of strain IR-S2. Aqueous As -tot $_{\text {concentra- }}$ tions increased with co-incubation of strain IR-ZA and AR-C1 after 18.0 days incubation, which is higher than the separated incubation of these two strains.

The effect of $\mathrm{As}(\mathrm{V})$ on DIR was also investigated, through incubation strain IR-S2 with different As/Fe molar ratio of As(V)-bearing ferrihydrite. The quantity of $\mathrm{Fe}$ (II) release was found to increase with the $\mathrm{As} / \mathrm{Fe}$ molar ratio of ferrihydrite. No Fe release or reduction was observed in the blank control.

\section{CONCLUSIONS}

Our results suggested that the microbial DIR in the groundwater aquifer enhance not only the release but also retention of arsenic. $\mathrm{Fe}(\mathrm{III})$ and $\mathrm{As}(\mathrm{V})$ reductions mediated by the indigenous bacteria were improved each other. Both microbial As reduction and reductive dissolution of $\mathrm{Fe}(\mathrm{III})$ oxyhydroxides were important mechanisms of As enrichment in groundwater aquifers in the Hetao Basin of Inner Mongolia.

\section{ACKNOWLEDGEMENTS}

The research work was financially supported by the National Natural Science Foundation of China (No. 41521001 and No.41772260).

\section{REFERENCES}

Dai, X.Y., Li, P., Tu, J., Zhang, R., Wei, D.Z., Li, B., Wang, Y.H. \& Jiang, Z. 2016. Evidence of arsenic mobilization mediated by an indigenous iron reducing bacterium from high arsenic groundwater aquifer in Hetao Basin of Inner Mongolia, China. Int. Biodeter. Biodegr. 128: 22-27.

Hungate, R.E. 1969. Chapter IV A roll tube method for cultivation of strict anaerobes. Method Microbiol. 3: 117-132. 